\title{
Circle of Willis of the brain: anatomical variations and their importance
}

\author{
Pasuk Mahakkanukrauh $^{1} \cdot$ Srijit Das $^{2}$
}

Received: 29 November 2015/ Accepted: 7 December 2015/Published online: 22 December 2015

(C) Japanese Association of Anatomists 2015

\section{Dear Editor,}

We read with much interest the recent published article entitled "A multitude of variations in the configuration of the circle of Willis: autopsy study" (Klimek-Piotrowska et al. 2015). We wish to share our scientific views on the published article.

We believe that the article would have benefited by the inclusion of a reference to the Polish cadaver study of Maga et al. (2013) in which the authors measured the Heubner artery of the brain. An important aspect of this study is the detailed description of just how the brains were dissected. A posterior approach through the foramen magnum allows not only easy retrieval of medulla and spinal cord but also facilitates dissection of the arteries.

It is important that authors state the exact number of observers who participate in recording the measurements and thereby potentially minimising the error. There is always an inquisitiveness on the part of any reader to know from which artery the third anterior cerebral artery originated. As there is shrinkage in the soft tissues of the body following death, especially in the blood vessels, the authenticity of the caliper measurements may be seen as a limitation relative to measurements by other, non-invasive procedures, such as Doppler which can measure the exact

Srijit Das

drsrijit@gmail.com

1 Osteology Research and Training Center (ORTC) \& Department of Anatomy, Faculty of Medicine, Chiang Mai University, 50200 Chiang Mai, Thailand

2 Department of Anatomy, Universiti Kebangsaan Malaysia Medical Centre, 18th Floor, Pre-Clinical Block, Jalan Yaacob Latif, Bandar Tun Razak, 56000 Cheras, Kuala Lumpur, Malaysia thickness of the blood vessels. It is difficult to label a vessel as hypoplastic when in fact it may have shrunken following death.

A discussion of the embryological factors potentially accounting for the presence of such anomalous arteries may have increased the importance of this cadaveric study. All blood vessels develop by vasculogenesis, and the branches sprout out by angiogenesis (Sadler 2015). Vascular endothelial growth factor and other growth factors also play an important role in the formation of normal arteries (Sadler 2015). The article may have benefitted from a more detailed discussion of these factors.

Overall, an interesting article. It is difficult to dissect the arteries of the brain in a meticulous manner, and we wish to applaud the work performed by the authors. The dissection photographs are excellent, and the classification of the arterial pattern is praiseworthy. We congratulate the authors and thank the editor for publishing such an important study.

Compliance with ethical standards

Conflict of interest Both authors have no conflicts of interests to declare.

Financial disclosure No funding was received for the study.

\section{References}

Klimek-Piotrowska W, Rybicka M, Wojnarska A, Wójtowicz A, Koziej M, Hołda MK (2015) A multitude of variations in the configuration of the circle of Willis: an autopsy study. Anat Sci Int. doi: 10.1007/s12565-015-0301-2

Maga P, Tomaszewski KA, Krzyżewski RM, Golec J, Depukat P, Gregorczyk-Maga I, Skrzat J (2013) Branches and arterial supply of the recurrent artery of Heubner. Anat Sci Int 88(4):223-229

Sadler TW (2015) Langman's medical embryology. Wolters Kluwer, China 